\title{
COMPARISON OF NON-SURVEY INPUT-OUTPUT ESTIMATES USING ALTERNATIVE REDUCTION TECHNIQUES
}

\author{
Curtis Braschler, Michael Procter and John A. Kuehn*
}

\section{Introduction}

Much has been written concerning the various procedures for regionalizing national input-output models (see reference list). This problem has become increasingly important as local governments and businessess are confronted with more difficult choices. Survey based input-output studies have become phohibitively expensive while the demand for applied economic analysis has expanded.

This paper presents a theoretical and empirical comparison of location quotient and supply-demand pool techniques for regionalizing national input-output systems. The 1972 national model was used in this study because it was the most recent available. This model has been substantially revised from older versions in terms of its basic mathematical formulation (see Interindustry Economics Division). The major conceptual difference in the 1972 version as compared to earlier versions is that the 1972 model is a commodity to industry output transformation rather than the traditional industry to industry transformation.

The primary concern in adapting the national I-O system to a region involves estimation of the regional export-import balance by commodity. The method chosen should be determined by the most realistic estimate of the export-import balance for each commodity.

Two measures are necessary to estimate a region's trade balance for individual commodities: (1) local commodity output and (2) local requirements for commodity output. Historically, location quotients and the supply-demand pooled procedure, with variations, (Schaffer and Chu) have been the primary methods for estimating local requirements for the output of a particular industry.

The purposes of this research are: (1) to compare these two major methods for estimating local requirements for the commodity output, (2) to indicate the relationship between the two methods, (3) to indicate how the two measures may be utilized together to improve the analysis of the local economy, and (4) to compare the results of applying the two different procedures in a particular case.

\section{The Model}

In order to examine the mathematical similarities and differences between the location quotient and the supply-demand pooled approaches to regionalization of the national input-output model, it is necessary to recall certain portions of the system in matrix notation. The key components of the I-O system include $\mathrm{i}$ commodities and $\mathrm{j}$ industries. Define:

$$
\text { (1) } \mathrm{U}=\mathbf{A X}
$$

where $U=(i x j)$ matrix in which each $U_{i j}$ represents the amount of commodity $i$ both nationally produced and imported that is used by industry $\mathrm{j}$ in the production of that industry's total output. (This matrix corresponds to the matrix $\mathrm{X}_{\mathrm{ij}}$ in the old formulation of industry by industry, where $\mathrm{X}_{\mathrm{ij}}$ represented the

*University of Missouri-Columbia 
total dollar amount of industry $i$ in dollars used in the total output of industry $j$. Upper case letters refer to national values and lower case to local values.)

$$
\text { (2) } \quad A=(\mathbf{i} \mathbf{~ j})
$$

matrix of direct requirements $A_{i j}$ of commodity $i$ used in production of one unit of output of industry $j$ (excluding value added), and

$$
\text { (3) } X=(j \mathbf{x})
$$

diagonal matrix formed from the national output $\mathrm{X}_{\mathrm{j}}$ vector.

Reduction of the national input-output system to a local economy is accomplished by assuming that local production functions for each industry are the same as at the national level. The appropriate reduction to local values depends upon the regional trade balance for commodity $i$.

An estimate of local output in commodity $i\left(x_{i}\right)$ is determined. A measure is then made of local requirements for the output of commodity $\mathrm{i}$. Location quotients and the supply-demand pool method are two practical alternatives for estimating local requirements as well as RAS. The ratio of local output to requirements is then determined. The value of this ratio determines the appropriate adjustment of the national coefficient. A ratio greater than one indicates the local economy is more than self sufficient in the output of commodity $i$ and has a surplus for export. The national technical coefficients are assumed to be valid for the region and no adjustment is necessary. A ratio of less than one indicates the output of commodity $i$ is insufficient for local needs. The national coefficients $A_{i j}$ or $U_{i j}$ are adjusted to local conditions by multiplying the ith ratio of local output to local requirements across all $\mathrm{j}$ columns. Hence, the ratio of local output to local requirements is critical both in determining when adjustments are to be made in national coefficients and in calculating the magnitude of those adjustments.

\section{Theoretical Relationship Between the Two Methods}

This paper considers and takes into account the work of Stevens and Trainer and Treyz and Ehrlich concerning the estimation of regional purchase coefficients and possible errors associated with these estimates. We carry the process further than these authors in showing empirically that a comparison of the estimates of regional purchase coefficients used in relation to an estimate of a regional output vector can provide additional information concerning the structure of a local economy. This is accomplished by comparing the ratios of the estimates of regional purchase coefficients determined from the pool method and the location quotient method. A comparison of estimates of regional purchase coefficients can substantially improve the analysis of the structure of the local economy.

In this section we will examine the relationship between location quotients and the supply-demand pool methods of determining the local requirements for the output of commodity $i$. The location quotient is defined as:

$$
\text { (4) } \quad \mathrm{LQ}_{\mathrm{i}}=(\mathrm{xi} / \mathbf{x}) /\left(\mathrm{X}_{\mathrm{i}} / \mathrm{X}\right)
$$

where:

$\mathrm{LQ}_{\mathrm{i}}=$ location quotient for commodity $\mathrm{i}$

$\mathbf{X}_{\mathbf{i}}=$ output of commodity $\mathbf{i}$ at the local level

$\mathbf{x}=$ total commodity output at the local level $\left(\Sigma_{\mathbf{i}} \mathbf{x}_{\mathbf{i}}\right)$

$\mathrm{X}_{\mathbf{i}}=$ output of commodity $\mathrm{i}$ at the national level

$\mathrm{X}=$ total commodity output at the national level.

Equation (4) can be rewritten as:

(5) $\mathrm{LQi}=\mathrm{xi}_{\mathrm{i}} /\left(\mathrm{xX}_{\mathrm{i}} / \mathrm{X}\right)=\left(\mathrm{x}_{\mathrm{i}} / \mathrm{X}_{\mathrm{i}}\right) /(\mathbf{x} / \mathrm{X})$

Let the quantity $\left(X_{i}-\mathbf{x} / \mathbf{X}\right)$ be designated si. The quantity si represents the local share of national commodity output. Its accuracy as a measure of local requirements assumes that the distribution of all 
commodities at the local level is the same as at the national level and that local final demand is proportional to national final demand. The quantity si may be a poor measure of local requirements for the output of commodity $i$ if these assumptions are not valid.

Now consider the quantity

$$
\text { (6) } d_{i}=\Sigma u_{i j}+\Sigma_{t} f_{i t}
$$

The quantity $U_{i j}$ is the estimated local requirements for commodity $i$ used in the production of the output of industry $\mathrm{j}$. Using the pool method, the matrix $u$ is computed from the equation.

$$
\text { (7) } \mathbf{u}=\mathbf{A} \cdot \mathbf{x}
$$

$\mathrm{A}$ is the national direct requirement coefficient matrix and $\mathbf{x}$ is a diagonal matrix with estimates of regional output by industry on the main diagonal and zeroes in all other positions.

The quantity fit represents local requirements for the ith commodity in the $t$ final demand category other than exports or federal government. In this particular study the local requirement of $i$ for consumption was computed by scaling the national consumption final demand vector by the ratio of total local earnings (BEA) to national total earnings or fic $=e / E \cdot F_{\text {ic }}$ where:

$f_{i c}=$ local final demand for ith commodity for consumption

$\mathrm{e}=$ total local earnings (BEA data)

$\mathrm{E}=$ total national earnings (BEA data)

$F_{\text {ic }}=$ national final demand for consumption

The local final demand vectors for capital goods and inventories were computed from national final demand vectors by scaling with the ratio of local output to national output (definitions and formulas for these quantities are discussed later in this paper). Finally, the local final demand vector for state and local government was computed by scaling the national final demand vector for state and local government by the ratio of total state and local government output to total national state and local government output.

The essential difference between the two values $\mathrm{Si}$ and $\mathrm{d}_{\mathrm{i}}$ is related to their computation. The location quotient value $\mathrm{Si}$ is used as a proxy for local requirements. The value $d_{i}$ is comprised of a sum of the mixed industries' requirements for commodity $i$ which is determined from the estimates of the mix of local output as measured by the value $\Sigma_{i} u_{i j}$ and of final demand requirements for commodity i ( $\left.\Sigma_{t} f_{i t}\right)$. The value $\Sigma_{j w i j} u_{i j}$ varies with relative compostion of the intermediate industry mix relative to the national intermediate industry mix. This is not true of the value si which assumes that the local mix or proportion of intermediate industry is the same as at the national level.

Even though $d_{i}$ includes final demand requirements, the following considerations mitigate this inconsistency between $d_{i}$ and $\mathrm{si}$. By making the assumption that local final demand functions are proportional to national final demand it is possible to use the quantitative relationship between the value of di and $\mathrm{Si}$ to make a more detailed evaluation of the structure of the local economy than can be made using either value alone. Initial estimates of final demand vectors, prior to reduction, were identical for both the LQ and the pooled comparisons. Third, reductions, if required, were applied to both intermediate and final demand vectors in both reduction approaches.

The established procedures for non-survey based input-output localization of the national model must assume that local production and consumptions functions are closely approximated by the national coefficients. To assume otherwise requires some kind of local evaluation or pre-study. The justification for localization or adjustment at the local level then arises from the need for imports when insufficient quantities of a commodity are produced locally to satisfy local demand. All procedures for regionalizing the national model must make these two assumptions prior to proceeding. If the investigator is not willing to make them, then he must be prepared to engage in a more detailed survey based study. However, it is recognized that the failure of one or more of these assumptions to hold locally would negate or at least detract from the validity of the conclusions reached in this study. Thus, any study, certainly including this one, which reaches tentative conclusions about the local economic structure should attempt to validate these conclusions before any policy recommendations are made. 
With the above caveats it is possible to use the quantitative relationship between the values of $\mathrm{si}$ and $d_{i}$ and the local measure of output of commodity $\mathbf{i}, \mathbf{x}$, to make some useful generalizations about the probable structure of the local economy.

In order to further develop a case for the use of both $\mathrm{si}$ and di, consider the following arguments. The location quotients approach assumes that the mix of all industries in the local economy is proportional to the national economy for self sufficiency. The quantity di accounts for the unique mix of industries at the local level. Thus, the pool approach uses existing secondary information regarding the local economy whereas the location quotient approach does not.

Local requirements are generated by multiplying the elements of local use matrix ( $\left.u_{i j}\right)$ by the ratios $\mathrm{x}_{\mathrm{i}} / \mathrm{di}_{\mathrm{i}}$ or $\mathrm{xi} / \mathrm{Si}$ when the appropriate ratio is less than one. When the ratio is greater than one, the national coefficients are used because the output of commodity $i$ is sufficient to meet local demand. In practice, the ratios $\mathrm{x}_{\mathrm{i}} / \mathrm{d}_{\mathrm{i}}$ and $\mathrm{xi}_{\mathrm{i}} / \mathrm{si}$ may not be consistent for a particular commodity (one ratio may indicate that a particular industry exports and the other that it imports). Four possible relationships between the two ratios are shown in Table 1. Further interpretations of the local economy can be made by a comparison of the two ratios in relation to the four possibilities outlined in Table 1.

The first issue involves choosing between the two ratios. The second concerns making use of both measures to provide more information about the local economy than either one used alone. It is necessary to examine the four different conditional relations between the reduction ratios. In addition, two subconditions are defined under condition 2 (Table 1). Under condition one (both $\mathrm{x}_{\mathrm{i}} / \mathrm{Si}_{\mathrm{i}}$ and $\mathrm{x}_{\mathrm{i}} / \mathrm{d}_{\mathrm{i}}$ greater than one), both methods imply exports and national coefficients are applied at the local level for the industry i. Since local requirements $\left(d_{i}\right)$ are less than actual output $\left(\mathbf{x}_{i}\right)$, a positive residual is guaranteed when exports are computed by the location quotient method.

Condition two presents the more interesting and difficult choice between the two methods. In this case both procedures indicate imports locally for the two methods. The problem becomes one of choosing the method which will most realistically adjust the national I-O model to the local conditions. If $\mathrm{di}_{\mathrm{i}}>\mathrm{si}$ (sub condition $2 \mathrm{a}$ ) then $\mathrm{x}_{\mathrm{i}} / \mathrm{di}_{\mathrm{i}}<\mathrm{xi}_{\mathrm{i}} / \mathrm{Si}$. If the pool approach is used, the resulting local use coefficient will be smaller than if the location quotient method is used. Use of the pool method results in larger estimated imports for commodity $\mathrm{i}$. In general, the more condition $2 \mathrm{a}$ prevails, the lower will multiplers be with the pool reduction than with the location quotient reduction.

If $\mathrm{si}_{i}>\mathrm{d}_{\mathrm{i}}$ then $\mathrm{x}_{\mathrm{i}}<\mathrm{x}_{\mathrm{i}} / \mathrm{d}_{\mathrm{i}}$ (sub-condition $2 \mathrm{~b}$ ), then location quotient reduction will yield smaller local use coefficients resulting in smaller multipliers than the pooled method, ceteris paribus. Obviously, the two methods yield the same results when $\mathrm{si}_{\mathrm{i}} / \mathrm{di}_{\mathrm{i}}=1$.

An examination of the values of $\mathrm{si}$ and di prior to choosing a reduction method can tell an investigator before hand what quantitative relationship will exist between the values produced by the two methods. The critical question is whether any particular significance can be attributed to the comparisons.

If $\mathrm{di}_{\mathrm{i}}>\mathrm{Si}$, then the local economy has a greater concentration of industries that are heavy users of $\mathrm{xi}_{\mathbf{i}}$

\section{TABLE 1}

Conditional Relations Between the Ratios of Pooled and Location Methods of Input-Output Reduction

\begin{tabular}{|c|c|c|c|c|}
\hline Ratio & $\begin{array}{c}\text { L.O. } \\
\text { Condition } \\
\mathbf{x}_{\mathrm{i} /} / \mathrm{F}_{\mathrm{i}}\end{array}$ & $\begin{array}{l}\text { L. } O \text {. } \\
\text { Export-Import }\end{array}$ & $\begin{array}{l}\text { Pooled } \\
\text { Condition } \\
\mathbf{x}_{\mathbf{i}} / \mathbf{d}_{\mathbf{i}}\end{array}$ & $\begin{array}{c}\text { Pooled } \\
\text { Export-Import }\end{array}$ \\
\hline Condition 1 & $\geqslant 1$ & Exports & $\geqslant 1$ & Exports \\
\hline Condition 2 & $<1$ & Imports & $<1$ & Imports \\
\hline \multicolumn{5}{|c|}{$\begin{array}{l}\text { a. } d_{i}>s \text {, larger imports, smaller multipliers, with } d_{i} \\
\text { b. } s_{i}>d_{i} \text { larger imports, smaller multipliers, with } \mathrm{si}\end{array}$} \\
\hline Condition 3 & $\geqslant 1$ & Exports & $<1$ & Imports \\
\hline Condition 4 & $<1$ & Imports & $\geqslant 1$ & Exports \\
\hline
\end{tabular}


than exists nationally. This is true even if both methods indicate local output to be insufficient for local demand $\left(\mathrm{x}_{\mathrm{i}} / \mathrm{di}_{\mathrm{i}}<\mathrm{xi}_{\mathrm{i}} / \mathrm{Si}_{\mathrm{i}}<1\right)$. The implications are somewhat paradoxical in the sense that the import requirements will be larger when estimated by the pool technique although the local economy may have a greater concentration of the users of commodity $i$ than the nation as implied by the LQ procedure. This raises the question as to why the local economy has not developed supporting capacity in output of $i$ to meet the demands from area industries that are large users of $x_{i}$. There might well be good reason, such as the importation of raw materials which do not exist locally, but the mathematical relations themselves do supply important information when examined together instead of separately.

If $\mathrm{si}_{\mathrm{i}}>\mathrm{di}_{\mathrm{i}}$ and $\mathrm{xi}_{\mathrm{i}} / \mathrm{Si}_{\mathrm{i}}<\mathrm{x}_{\mathrm{i}} / \mathrm{d}_{\mathrm{i}}<1$, then output of $\mathrm{xi}_{i}$ is insufficient to meet local requirements but industries using larger quantities of $\mathbf{x}_{i}$ for inputs are less concentrated in the area or less in proportion to the local economy than nationally. Adjustment of commodity $\mathrm{i}$ by the national share $\left(\mathrm{xi}_{\mathrm{i}} / \mathrm{si}_{\mathrm{i}}\right)$ might indicate requirements below the actual output $x_{i}$. This suggests exports for commodity $i$ in the region simply because the local mix was such that local requirements are actually less than the requirements indicated by the national share. This could be true even in the case where both ratios are less than one. The existence of positive exports using the location quotients reduction procedure when both reduction ratios are less than one simply indicates that local use requirements are excessively reduced by using the regional share measure because those industries using large quantities of $\mathrm{x}_{i}$ are less concentrated at the local level than at the national level.

Conditions three and four are the cases where the two reduction procedures give inconsistent answers. Under condition three the LQ ratio $\left(\mathrm{x}_{\mathrm{i}} / \mathrm{si}_{\mathrm{i}}\right)$ is greater than one which suggests that $\mathrm{x}_{\mathrm{i}}$ is an export industry for the local region. The pooled ratio $\left(\mathrm{xi}_{\mathrm{i}} / \mathrm{d}_{\mathrm{i}}\right)$ is less than one which suggests imports are needed locally. In this case, use of the si for reducing national coefficients results in negative exports for commodity $i$ after reduction to the local level. This implies that the local economy is much more specialized in those producing industries that are heavy users of $\mathrm{x}_{i}$ than in the national economy. The pool ratio would be the obvious choice for reduction in this case. Otherwise the use of $\mathbf{x}_{\mathbf{i}}$ locally would be grossly underestimated by the LQ ratio.

Condition four illustrates the opposite situation. In this case the LQ indicates imports while the pool ratio suggests exports. This suggests that the local economy is much less concentrated in industries that have a high utilization of $x_{i}$ than in the national economy. No adjustments should be made in the national coefficients under condition four.

\section{Empirical Comparison of the Two Methods}

The Missouri economy was analyzed using an aggregated version of the 1972 national input-output system (39 industries). Accurate estimation of Missouri commodity output by industry was not possible at the more disaggregated level of the national input-output system (Ritz).

Two methods were employed in developing estimates of commodity output of Missouri using U.S. economic census data and estimates of state and national earnings calculated by the Bureau of Economic Analysis, U.S. Department of Commerce. The first method (the national productivity approach) assumes that local output is a constant multiple of earnings in industry $j$, i.e.:

$$
\text { (8) } \quad \text { Nat Prod }{ }_{j}=O_{j} / E_{j}
$$

where nat prod $d_{j}$ is the national earnings multiple of industry $j$ and $O_{j}$ is national production of industry $j$ and $E_{j}$ is the national earnings in industry $j$. Missouri output of industry $j$ is then computed by the equation:

$$
\text { (9) } \operatorname{Moj}=\left(\text { Nat } \operatorname{prod}_{j}\right) e_{j}
$$

where Moj is Missouri output for industry $\mathrm{j}$ and $e_{j}$ is Missouri earnings for industry $\mathrm{j}$. This national productivity approach assumes that Missouri productivity is exactly the same as the national productivity for industry $\mathrm{j}$.

Where possible an alternative method was tried. This alternative developed an output multiple of industry earnings based on U. S. economic census data for output and was based on these equations:

(10) $\quad$ Mo prodi $=O_{j} / e_{j}$ 
where Mo prod $d_{j}$ is the state productivity ratio for industry $j$ based on census data, $O_{j}$ is state output for industry $j$ based on census data where available and $e_{j}$ is state earnings for industry $j$. Output for a year was computed from the following formula:

$$
\text { (11) } \text { outj }=\mathrm{O}_{\mathrm{j}} / \mathrm{ej}_{\mathrm{j}} \mathrm{ej}_{\mathrm{j}}
$$

where $e_{j}$ is the earnings in industry $j_{\text {. In this study out }}$ was used as the measure of industry output in 24 industries with available census data. The national productivity ratio was used to compute output for the remaining 15 industries. This compromise was used because the national productivity ratio had resulted in large discrepancies between output determinations as compared to census estimates. Commodity outputs $\left(\mathrm{x}_{\mathrm{i}}\right)$ were estimated using the 1972 national make tables.

Estimation of the local output was a major problem in this study and a highly aggregated version was used primarily for convenience and because of earnings data availability rather than any analytical justification. It was recognized that a more disaggregated estimate of regional commodity outputs would result in more useful and accurate evaluation of the Missouri economy. However, the major conclusion regarding superiority of the use of two measures of regional purchase coefficients in an evaluation of the local economy as compared to the use of either alone appears to be valid provided that the user is cognizant of any major product mix differences within national and local aggregated industry sectors.

Local requirements matrices for Missouri were determined using equation 7 . The values for $u_{i j}$ were determined and the local final demand vectors were determined as discussed above. The ratios $\mathrm{xi}_{\mathrm{i}} / \mathrm{di}_{\mathrm{i}}$ and $\mathbf{x i}_{\mathrm{i}} / \mathrm{si}$ were then used to determined the need for further adjustments in the local requirement matrices for Missouri. In each respective use the local requirement matrix and final demand vectors were adjusted for imports when the respective ratios $\left(\mathrm{x}_{\mathrm{i}} / \mathrm{di}_{\mathrm{i}}\right.$ or $\left.\mathrm{xi}_{\mathrm{i}} / \mathrm{si}_{\mathrm{i}}\right)$ were less than 1 by the equations developed below.

The 1972 national I-O tables were regionalized for the Missouri economy using the basic supplydemand pool procedure developed by Schaffer and Chu but adapted to the 1972 version with its substantial changes over the earlier national I-O tables. After determining a vector of estimates of Missouri output by industry for 1977 by the mixed procedure described above, the Missouri regional requirements matrix was determined using equation 7.

The matrix $\mathrm{u}$ was augmented with Missouri final demand estimates computed as described above. A Missouri scrap vector $h$ was computed by scaling the national scrap vector $H$ by the ratio of total Missouri output to total national output.

The regional make table was computed using the formula:

$$
\text { (12) } v_{i j}=V_{i j} / X_{j} \cdot X_{j}
$$

$\mathrm{v}_{\mathrm{ij}}=$ the regional Make Table elements

$V_{i j}=$ the national Make Table elements

$X_{j}=$ the national total industry $j$ output

$\mathrm{x}_{\mathbf{j}}=$ the regional total industry $\mathbf{j}$ output.

Regional trade balances were computed using the formula:

$$
\text { (13) } b_{i}=\left[x_{i}-\left(\Sigma_{i} u_{i j}+\Sigma_{t} f_{i t}\right)\right]
$$

$b_{i}=$ the regional trade balance of ith commodity,

$\mathbf{x i}_{\mathbf{i}}=$ the regional commodity output.

Regional commodity outputs, $\mathbf{x}_{\mathbf{i}}$, were determined using the national distribution of industry output $\mathbf{X}_{\mathbf{j}}$ distributed across commodities $\mathbf{X}_{\mathbf{i}}$ applied to regional industry output $\mathbf{X}_{\mathbf{j}}$. If $b_{i}$ is positive, then $b_{i}$ is the regional exports of commodity $i$ and if $b_{i}$ is negative the value is the regional imports of commodity $i$.

Regional imports of commodity i for the jth industry and $t$ final demand sector were computed for the pool approach by the formulas:

$$
\begin{aligned}
& m_{i j}=\left(\mid b_{i} / / d_{i}\right) \cdot u_{i j}=\left(\mid x_{i}-d_{i} / / d_{i}\right) \cdot u_{i j} \\
& m_{i t}=\left(\left|b_{i}\right| / d_{i}\right) \cdot f_{i t}=\left(\left|x_{i}-d_{i}\right| / d_{i}\right) \cdot f_{i t}
\end{aligned}
$$


$m_{i j}=$ the imports of commodity $i$ used in production of $j$ in the region.

$\mathrm{m}_{\mathrm{it}}=$ the imports of commodity $\mathrm{i}$ used in the $\mathrm{t}$ final demand of the region.

$\left|b_{i}\right|=$ the absolute value of the negative balance of trade values $b_{i}$.

The actual intermediate and final demand utilization of locally produced commodities were computed as follows:

$$
\begin{aligned}
& \text { (16) } \quad x^{a_{i j}}=u_{i j}-m_{i j} \\
& \text { (17) } f^{a_{i j}}=f_{i t}-m_{i t}
\end{aligned}
$$

$x^{a_{i j}}=$ adjusted use of commodity $i$ in the jth industry allowing for imports of commodity $i$ in the region, $\mathrm{m}^{\mathrm{a}_{\mathrm{j} j}}=$ adjusted use of commodity $i$ in the $t$ final demand sector for imports of commodity $i$ in the region. If commodity $i$ is exported, i.e., the region produces more of commodity $i$ than can be used locally, than $m_{i j}$ and $m_{i t}$ will be zero.

The regional value added by the jth industry was computed as follows:

$$
\text { (18) } \quad v a_{j}=x_{j}-\Sigma_{i x} a_{i j}-\Sigma_{i} m_{i j}
$$

$\mathrm{vaj}_{\mathrm{j}}=$ value added by $\mathrm{jth}$ industry

$\mathbf{x}_{\mathbf{j}}=$ estimated regional output of the jth industry.

In this analysis, the Missouri data were adjusted by both the pool and the location quotient procedure for comparative purposes. From a computational standpoint, this difference in adjustment was achieved in equations 14 and 15 . These equations show the computation necessary when the pool procedure is used. The substitution of the value $\mathrm{si}$ for the quantity di when the LQ is less than one results in the use of the location quotient procedure in the analysis. Other computations determining regional imports were the same as the pool procedure after the quantity $\mathrm{si}_{\mathrm{i}}$ was substituted for the quantity $\mathrm{d}_{\mathrm{i}}=\Sigma_{\mathrm{j}} \mathrm{u}_{\mathrm{ij}}+$ $\Sigma_{\text {tfit }}$ in equations 14 and 15 .

Regional exports were computed by the location quotients procedure as follows:

$$
\operatorname{REX}_{i}=\left[x_{i}-\left(\Sigma_{j} x^{a_{i j}}+\Sigma_{t} f_{i t}\right)\right]
$$

$\mathrm{REX}_{\mathrm{i}}=$ regional exports of commodity $i$.

$\mathrm{t}=$ final demand categories other than exports and federal government.

\section{Missouri Results}

Data for Missouri for 1977 were used to analyze the state economy using the 1972 national inputoutput tables. The location quotient and pool methods were used. Commodity outputs and the quantities $\mathrm{d}_{\mathrm{i}}$ and $\mathrm{si}$ were computed for all of the 39 commodities (Table 2 ). The ratios $\mathrm{xi}_{\mathrm{i}} / \mathrm{d}_{\mathrm{i}}, \mathrm{x}_{\mathrm{i}} / \mathrm{si}_{\mathrm{i}}$ and $\mathrm{si}_{\mathrm{i}} / \mathrm{d}_{\mathrm{i}}$ were computed along with the conditional relations between the three ratios discussed in the theoretical section of this paper. These relations are all shown in Table 2. Ten industries exibited condition one in which the ratios $\mathrm{x}_{\mathrm{i}} / \mathrm{d}_{\mathrm{i}}$ and $\mathrm{xi}_{\mathrm{i}} / \mathrm{Si}$ were consistent. In condition one no reduction of national coefficients is necessary.

In 23 industries condition two existed (both ratios were less than one, and were consistent in terms of dictating a need for adjusting national I-O coefficients). When condition two exists and the ratio $\mathrm{s} / \mathrm{d}_{\mathrm{i}}$ is greater than one, then the use of $\mathrm{xi} / \mathrm{Si}$ for reduction can result in gross positive exports for commodity i using equation 19 to compute exports even though the LQ is less than one (Table 3).

For farms, forestry, rubber and metal manufacturing condition two existed and in addition the ratio $\mathrm{si} / \mathrm{d}_{\mathrm{i}}$ was less than one. When condition two exists and the ratio $\mathrm{si}_{\mathrm{i}} / \mathrm{d}_{\mathrm{i}}$ is less than one, then the use of $\mathrm{xi}_{\mathrm{i}} /$ $\mathrm{Si}$ for reduction of national I-O values will result in negative exports for industry i when computed by standard methods. This suggests that the local economy has a greater concentration of industries that are heavier users of $\mathbf{x i}_{\mathbf{i}}$ than exists in the national economy and that the local output of $\mathbf{x}_{\mathbf{i}}$ is also below requirements as measured by both $d_{i}$ and $s i$. This condition suggests that an expansion of output in $x_{i}$ could be a serious contender for policy emphasis if economic growth is an objective of decision makers concerned with the local economy.

There were no industries in the Missouri economy with condition three (a ratio of $\mathrm{xi} / \mathrm{Si}$ greater than one and a ratio of $\mathrm{xi}_{\mathrm{i}} / \mathrm{di}_{\mathrm{i}}$ less than one) which would indicate the local economy has a much larger 
TABLE 2

Comparison of Pool and Location Quotient Results Missouri-1977

\begin{tabular}{|c|c|c|c|c|c|c|c|}
\hline Commodity & $\mathbf{x i}$ & $\mathrm{di}_{\mathrm{i}}$ & $\mathbf{S i}$ & $\mathbf{x}_{\mathbf{i}} / \mathbf{d}_{\mathbf{i}}$ & $\mathbf{X} / \mathbf{S i}$ & $\begin{array}{c}\text { Conditional } \\
\text { Relation } \\
\text { Between } \\
\text { Ratios } \\
\mathbf{x i}_{\mathbf{i}} / \mathrm{d}_{\mathrm{i}} \text { and } \\
\mathbf{x}_{\mathbf{i}} / \mathrm{si}\end{array}$ & $\begin{array}{l}\text { SIC } \\
\text { Codes }\end{array}$ \\
\hline FARMS & $2,450.18$ & $2,894.42$ & $2,828.93$ & 0.847 & 0.866 & $2 a$ & 01,02 \\
\hline FOREST & 19.41 & 108.58 & 84.86 & 0.179 & 0.229 & $2 a$ & 08,09 \\
\hline AGBUS & 140.49 & 137.20 & 157.03 & 1.024 & 0.895 & 4 & $02,07,08,09$ \\
\hline METALMIN & 300.46 & 136.44 & 132.32 & 2.202 & 2.271 & 1 & 10 \\
\hline COALMINE & 63.09 & 163.87 & 205.52 & 0.385 & 0.307 & $2 \mathrm{~b}$ & 11 \\
\hline OILGAS & 10.99 & 487.17 & 632.17 & 0.023 & 0.017 & $2 b$ & 13 \\
\hline QUARRY & 121.90 & 122.87 & 128.62 & 0.992 & 0.948 & $2 \mathrm{~b}$ & 14 \\
\hline CONST & $5,008.44$ & $5,624.70$ & $6,272.33$ & 0.890 & 0.798 & $2 \mathrm{~b}$ & $15,16,17$ \\
\hline FOODMFG & $5,990.95$ & $4,440.04$ & $4,557.76$ & 1.349 & 1.314 & 1 & 20 \\
\hline TOBACCO & 0.63 & 222.22 & 348.84 & 0.003 & 0.002 & $2 b$ & 21 \\
\hline TEXTILE & 790.89 & $1,698.85$ & $2,238.34$ & 0.466 & 0.353 & $2 b$ & 22,23 \\
\hline WOODMFG & 368.48 & 683.86 & 835.32 & 0.539 & 0.441 & $2 b$ & 24 \\
\hline FURNITUR & 305.31 & 410.22 & 417.87 & 0.744 & 0.731 & $2 \mathrm{~b}$ & 25 \\
\hline PAPERMFG & 835.30 & $1,024.77$ & $1,034.57$ & 0.815 & 0.807 & $2 \mathrm{~b}$ & 26 \\
\hline PRINTING & 633.32 & 542.81 & 630.83 & 1.167 & 1.083 & 1 & 27 \\
\hline CHEMICAL & $2,539.40$ & $1,858.16$ & $2,123.01$ & 1.367 & 1.196 & 1 & 28 \\
\hline PETROMFG & 653.23 & $1,108.76$ & $1,158.70$ & 0.589 & 0.564 & $2 \mathrm{~b}$ & 29 \\
\hline RUBBER & 501.03 & 872.03 & 795.05 & 0.575 & 0.631 & $2 a$ & 30 \\
\hline LEATHER & 569.18 & 292.48 & 210.96 & 1.946 & 2.698 & 1 & 31 \\
\hline STONEMFG & 827.16 & 792.80 & 794.21 & 1.043 & 1.041 & 1 & 32 \\
\hline METALMFG & $1,487.02$ & $3,067.93$ & $2,219.29$ & 0.485 & 0.670 & $2 a$ & 33 \\
\hline MACHINE & $1,727.61$ & $2,188.20$ & $2,407.58$ & 0.790 & 0.718 & $2 b$ & 35 \\
\hline ELECMACH & $1,899.44$ & $1,823.77$ & $2,001.65$ & 1.041 & 0.949 & 4 & 36 \\
\hline FABTRANS & $12,854.20$ & $6,202.53$ & $5,623.06$ & 2.072 & 2.286 & 1 & 34,37 \\
\hline INSTRU & 214.87 & 440.33 & 513.13 & 0.488 & 0.419 & $2 b$ & 38 \\
\hline MISCMFG & 235.30 & 409.21 & 428.56 & 0.575 & 0.549 & $2 b$ & 39 \\
\hline TRANSPOR & $3,735.24$ & $2,631.72$ & $2,895.04$ & 1.419 & 1.290 & 1 & $40-42,44-47$ \\
\hline COMMO & $1,171.45$ & $1,039.89$ & $1,158.85$ & 1.127 & 1.011 & 1 & 48 \\
\hline UTILITY & $2,283.99$ & $2,089.61$ & $2,206.03$ & 1.093 & 1.035 & 1 & 49 \\
\hline TRADES & $8,039.06$ & $7,459.42$ & $8,246.17$ & 1.078 & 0.975 & 4 & $50,51-57,59$ \\
\hline FINANCE & $2,705.53$ & $2,670.02$ & $2,927.21$ & 1.013 & 0.924 & 4 & $60-64$ \\
\hline REALEST & $3,053.33$ & $3,232.84$ & $3,711.71$ & 0.944 & 0.823 & $2 \mathrm{~b}$ & $65-66$ \\
\hline BUSSERV & $3,852.82$ & $4,085.63$ & $4,476.53$ & 0.943 & 0.861 & $2 \mathrm{~b}$ & $70,72,73,76,80$ \\
\hline EATDRINK & $1,326.84$ & $1,727.90$ & $1,840.98$ & 0.768 & 0.721 & $2 \mathrm{~b}$ & 58 \\
\hline AUTOREP & 530.25 & 894.39 & 927.67 & 0.593 & 0.572 & $2 \mathrm{~b}$ & 75 \\
\hline AMUSE & 432.01 & 420.31 & 480.59 & 1.028 & 0.899 & 4 & 78,79 \\
\hline PROFSERV & $3,193.77$ & $2,798.83$ & $3,207.99$ & 1.141 & 0.996 & 4 & $80,82-84,86$ \\
\hline FEDENT & 307.18 & 321.05 & 361.53 & 0.957 & 0.850 & $2 \mathrm{~b}$ & Enterprises \\
\hline SLGOVENT & 80.71 & 96.47 & 105.76 & 0.837 & 0.763 & $2 b$ & Enterprises \\
\hline
\end{tabular}


TABLE 3

Comparison of Estimated Interregional Trade Flows-

Pool Vs. Location Quotient

\begin{tabular}{|c|c|c|c|c|}
\hline \multirow[b]{2}{*}{ Commodity } & \multicolumn{2}{|c|}{ Exports } & \multicolumn{2}{|c|}{ Imports } \\
\hline & Pool & LQ & Pool & LQ \\
\hline FARMS & 0.00 & -56.73 & 444.24 & 387.52 \\
\hline FOREST & 0.00 & -5.42 & 89.17 & 83.75 \\
\hline AGBUS & 3.29 & 17.74 & 0.00 & 14.46 \\
\hline METALMINE & 164.02 & 164.02 & 0.00 & 0.00 \\
\hline COALMINE & 0.00 & 12.79 & 100.78 & 113.56 \\
\hline OILGAS & 0.00 & 2.52 & 476.18 & 478.70 \\
\hline QUARRY & 0.00 & 5.45 & 0.97 & 6.42 \\
\hline CONST & 0.00 & 517.13 & 616.26 & $1,133.39$ \\
\hline FOODMFG & $1,550.91$ & $1,550.91$ & 0.00 & 0.00 \\
\hline TOBACCO & 0.00 & 0.23 & 221.59 & 221.82 \\
\hline TEXTILE & 0.00 & 190.62 & 907.96 & $1,098.59$ \\
\hline WOODMFG & 0.00 & 66.82 & 315.38 & 382.19 \\
\hline FURNITUR & 0.00 & 5.60 & 104.91 & 110.50 \\
\hline PAPERMFG & 0.00 & 7.91 & 189.47 & 197.38 \\
\hline PRINTING & 90.51 & 90.51 & 0.00 & 0.00 \\
\hline CHEMICAL & 681.24 & 681.24 & 0.00 & 0.00 \\
\hline PETROMFG & 0.00 & 28.15 & 455.53 & 483.68 \\
\hline RUBBER & 0.00 & -48.55 & 370.65 & 322.10 \\
\hline LEATHER & 276.70 & 276.70 & 0.00 & 0.00 \\
\hline STONEMFG & 24.36 & 34.36 & 0.00 & 0.00 \\
\hline METALMFG & 0.00 & -568.62 & $1,580.91$ & $1,012.29$ \\
\hline MACHINE & 0.00 & 157.42 & 460.59 & 618.01 \\
\hline ELECMACH & 75.67 & 168.80 & 0.00 & 93.13 \\
\hline FABTRANS & $6,651.67$ & $6,651.67$ & 0.00 & 0.00 \\
\hline INSTRU & 0.00 & 30.48 & 225.46 & 255.94 \\
\hline MISCMFG & 0.00 & 10.62 & 173.91 & 184.53 \\
\hline TRANSPOR & $1,103.52$ & $1,103.52$ & 0.00 & 0.00 \\
\hline COMMO & 131.56 & 131.56 & 0.00 & 0.00 \\
\hline UTILITY & 194.38 & 194.38 & 0.00 & 0.00 \\
\hline TRADES & 579.64 & 766.99 & 0.00 & 187.35 \\
\hline FINANCE & 35.51 & 237.71 & 0.00 & 202.20 \\
\hline REALEST & 0.00 & 393.94 & 179.51 & 573.44 \\
\hline BUSSERV & 0.00 & 336.43 & 232.81 & 569.25 \\
\hline EATDRINK & 0.00 & 81.50 & 401.06 & 482.56 \\
\hline AUTOREP & 0.00 & 19.02 & 364.14 & 383.16 \\
\hline AMUSE & 11.70 & 54.19 & 0.00 & 42.49 \\
\hline PROFSERV & 394.95 & 407.36 & 0.00 & 12.41 \\
\hline FEDENT & 0.00 & 34.39 & 13.87 & 48.26 \\
\hline SLGOVENT & 0.00 & 7.09 & 15.76 & 22.85 \\
\hline
\end{tabular}


concentration of industries that are heavier users of commodity $\mathbf{x}_{\mathbf{i}}$ than exists nationally.

The Missouri economy in 1977 had 6 industries with condition four $\left(\mathrm{xi}_{\mathrm{i}} / \mathrm{si}\right.$ was less than one and $\mathrm{xi}_{\mathrm{i}} / \mathrm{di}_{\mathrm{i}}$ was greater than one). Agribusiness, electrical machinery, trades, finance, amusement and professional service were all condition four industries. This suggests the possibility that the Missouri economy was less concentrated in industries having a high utilization of these commodities than the national economy. Such a relation could also be caused by a different mix within a sector than is the case nationally. This possibility is more likely in studies such as this where sectors were highly aggregated. The existence of condition four suggests some possibilities to consider in a more detailed type of study.

Interregional trade flows (exports and imports) were estimated using the two reduction methods for the Missouri economy (Table 3). There were no commodities with zero exports as measured by the LQ procedure. Four commodities showed negative exports as measured by the LQ methods. It should be noted that these were those commodities with sub-condition $2 \mathrm{a}$ where the value of $\mathrm{si} / \mathrm{d}_{\mathrm{i}}$ is less than one (Tables 1, 2 and 3).

A comparison was also made of the type II multipliers generated by the two reduction methods. These results are shown in Table 4. In all but one case, the type II multiplier was larger for the pool than for the location quotient technique (Table 4). This appears to be the usual case and is consistent with the pool method as a maximum measure of intraregional trade assuming no cross hauling of product. However, it should be noted that the LQ approach bears no theoretical relation to cross hauling either. Recently Stevens has used econometric models to estimate cross hauling.

In general, the location quotient reduction method resulted in smaller multipliers than the pool method in this study. These differences were not large when compared on a percentage difference basis (Table 4). Overall, the pool method results in higher multipliers because it generates an overall smaller estimate of imports regionally than does the LQ method. From a theoretical standpoint the case can be made for the use of the pool reduction procedure coupled with the LQ coefficients for a further evaluation of the local economy. Both methods result in larger estimates of multipliers than survey based estimates. However, since LQ multipliers are smaller and have usually overestimated multipliers less than the pool procedure when compared to survey estimates, the LQ method has generally been used.

This analysis suggests that use of both methods furnishes information not generated by either procedure used alone. From a theoretical standpoint, the regional multipliers estimated from the pool procedure should not be biased upward primarily because nonsurvey estimates have not generally been adjusted for cross hauling effects. If the necessary assumptions (national production functions apply and final demands proportional to the national levels) are met, then the pool method adjusted for cross hauling should provide regional multipliers more nearly accurate and closer to survey based analysis. Both pool and survey procedures would still be subject to measurement error. This study did not attempt to investigate these theoretical arguments but it suggests that another study or studies should be done.

Although the examination of any single industry condition as defined in Table 1 will not serve as much of an indicator of the overall magnitude of multiplier differences between the $L Q$ and pool reduction procedures, the existence of several condition four industries would tend to widen the discrepancies between overall regional multipliers estimated by the two procedures, ceteris paribus. This is true since condition four industries import using LQ reduction and export using the pool technique. Condition three would indicate the opposite but no condition three industries were identified by this study.

\section{Conclusions}

Two major conclusions can be drawn from this analysis. The pool method is preferable to the location quotient method on theoretical grounds because the pool reduction technique takes the local industry mix into account. Location quotients are apparently more often used because estimates of multipliers are closer to survey based studies. The pool technique is a maximum measure of intraregional trade and multipliers since the pool method assumes no cross hauling. In reality cross hauling will occur regardless of the local reduction technique chosen and will reduce intraregional trade, along with industry multipliers. Neither method examines the cross hauling issue directly, but the arguments developed in this paper suggest that accurate assessment of cross hauling would give the pool procedure an edge in making final estimates of regional multipliers. 
TABLE 4

Comparison of Total Type II Multipliers Missouri - 1977

\begin{tabular}{|c|c|c|c|c|}
\hline Sector & Pool & LQ & Pool-LQ & $\begin{array}{r}(\text { Pool-LQ)/ } \\
\text { LQ x } 100\end{array}$ \\
\hline FARMS & 3.84 & 3.71 & 0.13 & 3.5 \\
\hline FOREST & 3.16 & 3.04 & 0.12 & 3.9 \\
\hline AGBUS & 4.11 & 3.92 & 0.19 & 4.8 \\
\hline METALMIN & 2.90 & 2.79 & 0.11 & 3.9 \\
\hline COALMINE & 4.01 & 3.80 & 0.21 & 5.5 \\
\hline OILGAS & 3.31 & 3.15 & 0.16 & 5.1 \\
\hline QUARRY & 3.22 & 3.09 & 0.13 & 4.2 \\
\hline CONST & 3.44 & 3.31 & 0.13 & 3.9 \\
\hline FOODMFG & 3.73 & 3.64 & 0.09 & 2.5 \\
\hline TOBACCO & 2.49 & 2.41 & 0.08 & 3.3 \\
\hline TEXTILE & 3.57 & 3.26 & 0.31 & 9.5 \\
\hline WOODMFG & 3.20 & 3.01 & 0.19 & 6.3 \\
\hline FURNITUR & 3.38 & 3.23 & 0.15 & 4.6 \\
\hline PAPERMFG & 3.39 & 3.23 & 0.16 & 5.0 \\
\hline PRINTING & 3.76 & 3.59 & 0.17 & 4.7 \\
\hline CHEMICAL & 3.44 & 3.30 & 0.14 & 4.2 \\
\hline PETROMFG & 1.96 & 1.89 & 0.07 & 3.7 \\
\hline RUBBER & 3.38 & 3.25 & 0.13 & 4.0 \\
\hline LEATHER & 3.88 & 3.71 & 0.17 & 4.6 \\
\hline STONEMFG & 3.28 & 3.15 & 0.13 & 4.1 \\
\hline METALMFG & 3.08 & 3.16 & -0.08 & -2.5 \\
\hline MACHINE & 3.39 & 3.33 & 0.06 & 1.8 \\
\hline ELECMACH & 3.61 & 3.51 & 0.10 & 2.8 \\
\hline FABTRANS & 3.12 & 3.12 & 0.00 & 0.0 \\
\hline INSTRU & 3.66 & 3.54 & 0.12 & 3.4 \\
\hline MISCMFG & 3.67 & 3.56 & 0.11 & 3.1 \\
\hline TRANSPOR & 3.49 & 3.34 & 0.15 & 4.5 \\
\hline COMMO & 2.86 & 2.72 & 0.14 & 5.1 \\
\hline UTILITY & 2.74 & 2.61 & 0.13 & 5.0 \\
\hline TRADES & 3.28 & 3.13 & 0.15 & 4.8 \\
\hline FINANCE & 3.81 & 3.56 & 0.25 & 7.0 \\
\hline REALEST & 1.82 & 1.73 & 0.09 & 5.2 \\
\hline BUSSERV & 3.54 & 3.36 & 0.18 & 5.4 \\
\hline EATDRINK & 4.05 & 3.90 & 0.15 & 3.8 \\
\hline AUTOREP & 3.55 & 3.43 & 0.12 & 3.5 \\
\hline AMUSE & 3.47 & 3.24 & 0.23 & 7.1 \\
\hline PROFSERV & 3.97 & 3.77 & 0.20 & 5.3 \\
\hline FEDENT & 3.19 & 3.05 & 0.14 & 4.6 \\
\hline SLGOVENT & 3.17 & 2.99 & 0.18 & 6.0 \\
\hline
\end{tabular}

The use of both measures can provide more information about the actual structure of a local economy than either measure used separately. A comparison of the reduction ratios in terms of the four possible conditions outlined in this study can provide an analyst with a useful starting point for evaluating the structure of a particular local economy. Some questions that can be initially addressed would include:

1. The potential for increasing the output of a commodity $i$ if local shortages of the output of $i$ are 
the result of a heavy regional concentration of industries using outputs of commodity $i$. This situation especially exists under condition three $\left(\mathrm{x}_{\mathrm{i}} / \mathrm{Si}_{\mathrm{i}}>1, \mathrm{x}_{\mathrm{i}} / \mathrm{d}_{\mathrm{i}}<1\right)$. No examples were found to exist in this study, but could in a particular local situation. Growth of $x_{i}$ under such a condition would appear to be an obvious growth opportunity to more nearly satisfy local demand for output of $\mathbf{x}_{i}$; and a question is raised as to why output of $x_{i}$ is below local demand given a heavier than national concentration of industries using $\mathbf{x i}$.

2. The potential for increasing the concentration of industries that are heavy users of the commodity $\mathrm{i}$ (condition four where $\mathrm{x}_{\mathrm{i}} / \mathrm{Si}_{\mathrm{i}}<1, \mathrm{xi}_{\mathrm{i}} / \mathrm{di}_{\mathrm{i}}>1$ ). This condition suggests that the local economy is much less concentrated in industries that have a high demand for $\mathbf{x}_{i}$ than is true nationally. Six Missouri industries were found to exhibit this condition (agribusiness, electrical machinery, trades, finance, amusement and professional services). If a locality is growth oriented, expanding local industries using these commodities could be a promising approach because a support industry is currently exporting output from the region which could be used by local industries as inputs. This should be regarded only as an indicator for further study because the deviation of local industry mix from the national may be justified for sound economic reasons, or the apparent deviation could be distorted by differences in product mix within sectors.

It should be noted that a simple comparison of local industry mix with national industry mix does not result in the same information that results from a comparison of the local ratios $\mathrm{x}_{\mathrm{i}} / \mathrm{di}_{\mathrm{i}}$ and $\mathrm{x}_{\mathrm{i}} / \mathrm{si}_{\mathrm{i}}$ because only a comparison of these two ratios can relate the possible discrepancies between actual output of commodity $i$ locally and the potential local demand. It should be noted that some type of survey or other analysis is needed to provide adjustments in local export-import balances that would always be expected from cross hauling. This study did not address this question empirically but recognizes the issue. Neither of the methods used in this study addresses the issue of cross hauling . Finally, the possibility of a deviation of local production and consumption functions from national functions should always be investigated before any specific policy recommendations are made based on comparisons of regional purchase coefficient estimates derived from the location quotient and pool estimation procedures.

\section{REFERENCES}

Henry, Mark, "A Note on Non-Survey Input-Output Models for Multicounty Regions," Review of Regional Studies, Vol. 10, No. 1, 1980, pp. 68-71.

Interindustry Economics Division, "Mathematical Derivation of the Total Requirements Tables for the 1972 Input-Output Study," Washington, D.C.: Bureau of Economic Analysis, U.S. Department of Commerce, February 1979, mimeograph.

Jensen, R.C., "The Concept of Accuracy in Regional Input-Output Models," International Regional Science Review, Vol. 5, No. 2, 1980, pp. 139-54.

McMenamin, David G. and Joseph E. Haring, "An Appraisal of Non-survey Techniques for Estimating Regional Input-Output Models," Journal of Regional Science, Vol. 14, 1974, pp. 191-206.

Morrison, W.I. and P. Smith, "Non-Survey Input-Output Techniques at Area Level: An Evaluation," Journal of Regional Science, Vol. 14, No. 1, 1974, pp. 1-14.

Park, Se-Hark, Malek Mohtadi, and Atif Kubursi, "Errors in Regional Non-Survey Input-Output Models: Analytical and Simulation Results," Journal of Regional Science, Vol. 21, No. 3, 1981, pp. 321-37.

Ritz, Philip M., Eugene P. Roberts, and Paula C. Young, "Dollar-Value Tables for the 1972 Input-Output Study," Survey of Current Business, Vol. 39, No. 4, pp. 51-72.

Stevens, Benjamin H. and Glynnis A. Trainer, "Error Generation in Regional Input-Output Analysis and the Implications for Non-Survey Models," Regional Science Research Institute Discussion Paper Series: No. 108, December 1978.

Stevens, Benjamin H., George I. Treyz, and David J. Ehrlich, "On the Estimation of Regional Purchase Coefficients, Export Employment, and Elasticities of Response for Regional Economic Models," Regional Science Research Institute Discussion Series: No. 114, December 1979.

Schaffer, William A. and Kong Chu "Non-Survey Techniques for Constructing Regional Interindustry Models," Papers, Regional Science Association, Vol. 23, 1969, pp. 83-101.

U.S. Department of Commerce, Bureau of Economic Analysis, Definitions and Conventions Underlying the 1972 National InputOutput Study. 